\title{
POLÍTICAS EDUCACIONAIS E DESIGUALDADES: À PROCURA DE NOVOS SIGNIFICADOS
}

\author{
Miguel G. Arroyo*
}

RESUMO: O texto destaca como as políticas educacionais têm sido instigadas pelas tentativas de corrigir as desigualdades. Entretanto, ao centrarem-se nas desigualdades intraescolares, as políticas e suas análises se empobrecem. Mas se enriquecem na medida em que avançam na compreensão dos processos históricos de produção-reprodução das desigualdades sociais. O texto se defronta com uma indagação: que mudanças na formulação e nas análises de políticas quando as desigualdades revelam uma nova qualidade? Quando os coletivos feitos tão desiguais se afirmam como sujeitos de políticas? Nesse novo quadro, o texto avança indagando como é pensado o Estado e como são pensados os coletivos sociais feitos desiguais. Qual o novo papel do Estado e de suas políticas na gestão-controle dos processos de afirmação política desses coletivos. Estaríamos avançando para a refundação do Estado e das políticas?

Palavras-chave: Políticas educacionais. Desigualdades sociais e educativas. Novos sujeitos sociais. Refundação do Estado.

\section{EDUCATIONAL POLICIES AND INEQUALITIES:} LOOKING FOR NEW MEANINGS

ABSTRACT: This paper highlights how educational policies have been motivated by attempts to fight inequalities. However, since they focus on intraschool inequalities, such policies and their analyses are impoverished. Yet they are enriched since they progress in the

Doutor em Educação e professor titular emérito da Faculdade de Educação da Universidade Federal de Minas Gerais (UFMG). E-mail: gn.arroyo@gmail.com 
understanding of the historical processes of production-reproduction of social inequalities. This text is faced with some questions: what should change in the policy formulation and analyses when inequalities have a new quality? When collectives made so unequal affirm themselves as policy subjects. In this new framework, this paper advances wondering how the State is thought and how collectives made unequal are thought. What is the new role of the State and of its policies in the management-control of the processes of political affirmation of these collectives? Are we heading to the refoundation of the State and of the policies?

Key words: Educational policies. Social and educational inequalities. New social subjects. Refoundation of the State.

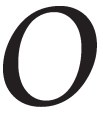

$s$ estudos, as pesquisas e os debates sobre a relação entre educação e desigualdades têm sido um dos campos mais fecundos e instigantes no pensamento educacional progressista e na formulação e gestão, na análise e avaliação de políticas educativas.

Essa relação tem merecido ênfases bastante diferenciadas. As pesquisas, avaliações e as análises de políticas têm se concentrado no entendimento e superação das desigualdades no próprio campo da educação escolar: analfabetismo, baixos níveis de escolarização, defasagens, evasões, repetências, desigualdades de percursos escolares. $\mathrm{Na}$ década de 1990, o destaque passou a ser as desigualdades de acesso e de permanência. Toda criança na escola. Mais recentemente, se avança para as desigualdades de aprendizagem, de qualidade dos percursos.

Sistemas nacionais e internacionais de avaliação expõem e confrontam as desigualdades educativas entre coletivos e escolas públicas e privadas, entre municípios, estados, nações, Norte-Sul. Avaliações das desigualdades educacionais medidas e quantificadas cada vez com maior requinte e expostas pela mídia, mostrando a vergonha das diversidades de qualidade de nossa educação; mostrando, sobretudo, os coletivos sociais, regionais, raciais, do campo, que desmerecem a qualidade de nosso sistema educacional público. As desigualdades educacionais como vergonha nacional, como mancha e expressão de nosso atraso. Até como causa de nosso subdesenvolvimento nacional, regional, social, cultural, político e econômico. A cada proclamação enfática dos resultados das avaliaçóes, o próprio Estado reconhece que nossos sonhos de reduzir as desigualdades estão distantes. 
Corrigir as desigualdades educacionais perpassa as justificativas de todas as políticas. Mostrar o pouco que se avançou, se retrocedemos e o que planejar, que estratégias e que intervenções no sistema escolar, na formação docente para corrigir as desigualdades no próximo decênio. O fantasma dessas desigualdades perturbando nossos sonhos de República, de democracia, de justiça e equidade. Talvez seja a relação mais persistente tanto no pensamento conservador ou liberal, como no progressista. Porque as desigualdades continuam persistentes. Incômodas. Uma relação que tem instigado pesquisas, teses, dissertações, produção teórica, mostrando a diversidade de fatores determinantes de sua persistência.

Avançamos na compreensão dos complexos processos de produção-reprodução das desigualdades. Entretanto, esses acúmulos de estudos nem sempre foram levados em conta na formulação e gestão, nas análises e avaliações, nem nas justificativas de diretrizes, de intervenções de políticas que se propõem corrigi-las. Privilegiam-se resultados mensuráveis de avaliações oficiais generalistas, parciais, impressionistas. $\mathrm{O}$ praticismo político de resultados tem ignorado a profundidade de análises acumuladas nos centros de pesquisa e de pós-graduação.

Ao pensamento sócio-pedagógico mais crítico das últimas décadas devemos ter levado as análises das desigualdades educacionais para além dos supostos determinantes intraescola e intrassistema, para os determinantes sociais, econômicos, políticos, culturais, de gênero, raça, etnia, campo, periferia. Avançando até as determinações dos padrôes de poder, trabalho, acumulação, concentração-exclusão da terra e da renda. Sabemos mais sobre como esse conjunto de desigualdades históricas condiciona as desigualdades educacionais. Análises demasiado incômodas para a paz das instituiçóes educativas gestoras e formuladoras de políticas, de avaliações e de análises. Nas últimas décadas avançamos em mostrar essas estreitas relações entre desigualdades. Um avanço de extrema relevância.

Entretanto, essas análises não conseguiram sensibilizar órgãos gestores, de planejamento, formulação de políticas e de avaliações. O foco continua fechado na exposição das desigualdades escolares e na denúncia dos fatores intraescolares como responsáveis pela sua persistência. O foco estreito continua responsabilizando os professores e até os próprios educandos. Seriam os agentes do ensinar-aprender, 
uns fingindo ensinar e outros aprender, os responsáveis por não termos um sistema escolar capaz de superar as desigualdades de nosso país.

As pesquisas e análises sérias que apontam outras causas mais determinantes, inclusive intrassistema escolar, são ignoradas. Como não são levadas a sério pesquisas que mostram o papel histórico do próprio sistema, a reprodução das desigualdades, sobretudo, são ignoradas as análises e pesquisas que mostram o peso determinante das desigualdades sociais, regionais, raciais, sobre as desigualdades escolares na formulação de políticas, na sua gestão e avaliação. A repolitização conservadora na sociedade, na política e na formulação e avaliação de políticas fechou o foco no escolar, ignorando os determinantes sociais, econômicos, ou as desigualdades tão abismais nesses campos como determinantes das desigualdades educacionais. Esse fechar conservador do foco no intraescolar, ignorando as relações educação-sociedade, está levando a gestão de políticas, sua formulação, avaliação e análise a um empobrecimento lamentável. Preocupante, mas também instigante.

Torna-se urgente retomar a centralidade da relação entre educação e sociedade que tanto fecundou o pensamento sócio-educativo, as políticas e suas análises. Relação que se mostra mais complexa com o aumento do acesso à escola dos filhos e das filhas dos coletivos feitos e mantidos tão desiguais em nossa história. É preocupante que, na medida em que os mais desiguais chegam ao sistema escolar expondo as brutais desigualdades que os vitimam, as relações educação-políticas-desigualdades fiquem secundarizadas e sejam priorizadas políticas de inclusão, de qualidade, de padrões mínimos de resultados.

É urgente retomar essa relação não superada entre educação e desigualdades. Primeiro, porque foi uma das relações mais instigantes do pensamento educacional. Segundo, porque essa relação foi desfigurada e soterrada nos escombros de relaçóes de mercado, de educação e padrão mínimo de qualidade, de currículos por competências, gestão e avaliaçôes de resultados. Terceiro, porque as desigualdades não só continuam, mas se aprofundam e vitimam milhões de famílias e alunos(as) pela miséria, o desemprego, a sobrevivência nos limites, a violência. As desigualdades dos coletivos sem-teto, sem-terra, sem-espaço, sem-comida, semuniversidade, sem-territórios entram na escola como nunca antes e interrogam as políticas educativas, sua gestão e suas análises. 
Sobretudo essa relação tem de ser retomada em um quadro social, político e cultural novo: as vítimas das nossas históricas desigualdades sociais, étnicas, raciais, de gênero, campo, periferias se fazem presentes, afirmativas, incômodas, não apenas nas escolas, mas na dinâmica social e política. A relação educação-desigualdades, tão abstrata e genérica, exige ser recolocada na concretude dos coletivos feitos desiguais, reagindo às desigualdades e se apresentando e afirmando como sujeitos políticos, de políticas, de afirmações positivas.

Diante desse novo quadro político, a relação educação-coletivos em reação às desigualdades se torna mais complexa e aponta indagações novas para a educação, para o sistema educacional, para sua gestão e para a formulação, avaliação e análise de políticas. Aponta confrontos políticos na esfera pública, pressionando por outras funções do público e do Estado. Uma dinâmica política nova no campo das desigualdades ou dos coletivos pensados e segregados como desiguais na história de nossa formação; nova nas relaçōes entre esses coletivos feitos desiguais e o Estado, suas instituiçōes e suas políticas sócio-educativas. Como repensar o Estado, suas instituiçōes, suas política, em confronto com as desigualdades e os coletivos feitos desiguais, quando eles se afirmam como sujeitos de políticas?

Partimos da hipótese de que o dinamismo no campo das políticas e de suas análises e propostas virá do reconhecimento das mudanças profundas, tensas, que estão postas na dinâmica social pelos próprios coletivos pensados e feitos desiguais. A nova qualidade das desigualdades concretas e a nova presença dos coletivos feitos desiguais, se reconhecidas em sua centralidade política, poderão redefinir as formas de pensá-los, de pensar a produção das desigualdades e de pensar as políticas de igualdade e suas análises. De se pensar o próprio Estado e suas instituiçōes públicas.

A relação entre políticas educativas e desigualdades perde seus significados ou aponta novos? Tentemos avançar na procura desses novos significados políticos.

Como o Estado se pensa e como são pensados os coletivos feitos desiguais

Comecemos por um ponto nuclear nas análises de políticas: como é pensado o Estado e como são pensados os coletivos desiguais. 
$\mathrm{Na}$ formulação, gestão e análise da relação entre políticas educacionais e desigualdades entram em jogo as formas de pensar os coletivos feitos desiguais e as formas de pensar o Estado. Predominam análises onde o Estado é o centro. A sociedade e especificamente os coletivos feitos desiguais aparecem como meros destinatários das ações e intervenções políticas do Estado. As desigualdades, vistas sem sujeitos, entram apenas como campo de intervenção. Enfatizam-se as desigualdades a corrigir e os deveres do Estado, mas se ignoram os sujeitos, indivíduos e coletivos produzidos como desiguais. A relação privilegiada será Estado, políticas e instituições públicas e correção das desigualdades em abstrato. Sem rostos de sujeitos.

Fazer análises da relação entre Estado, políticas públicas e coletivos feitos desiguais seria bem mais complexo do que continuar relacionando educação, políticas e desigualdades genéricas. $\mathrm{O}$ foco nos coletivos feitos desiguais redefine as desigualdades. Eles têm classe, raça, etnia, gênero, lugar. As desigualdades em abstrato não têm rosto, nem cor, nem gênero ou classe. As consequências desse trato abstrato, genérico, das desigualdades têm sido sérias para a formulação de políticas, de sua gestão e análise. Predominam políticas generalistas, para todos, como corresponde a visão republicana do público e da ação do Estado. O único sujeito da ação será o Estado, suas políticas, suas instituições e seus gestores que se propóem resolver as desigualdades. Os coletivos feitos desiguais são ignorados nessas análises e na gestão e formulação de políticas de superação de desigualdades genéricas. Consequentemente, a história dos processos de produzi-los como desiguais é ignorada. As políticas mostram o protagonismo ou a ausência do Estado. A função das análises de políticas será lembrar seu dever de intervir na correção das desigualdades genéricas.

Em realidade, prestando atenção a essas análises, não conseguem esquecer os sujeitos que padecem as desigualdades. Aparecem como destinatários passivos, agradecidos, à espera de entrar no reino da igualdade propiciada pelo Estado e suas políticas sócio-educativas. Os coletivos feitos desiguais pensados na imagem do Estado benevolente, protetor dos desiguais. Sem eles, como cultuar essa visão do Estado, de suas políticas e instituições e da ação do corpo de gestores empenhados por décadas em superar as desigualdades? Mas também o Estado é pensado na imagem dos desiguais. Poderíamos levantar a hipótese de que a imagem benevolente, compassiva do Estado e de suas instituições 
e políticas, precisa para se cultuar da produção da imagem dos coletivos feitos desiguais e da persistência das desigualdades. As formas como o Estado se pensa ou como é pensado nos centros de formulação e gestão de políticas sócio-educativas têm como espelho, como referente, as formas de pensar os coletivos desiguais.

Por aí poderíamos apontar a urgência de analisar como foram e continuam sendo pensados os coletivos feitos desiguais para entender como o Estado se pensa e como as políticas de correção das desigualdades são pensadas. Consequentemente, deveríamos aprofundar como o Estado se pensa para entender como os desiguais são pensados. Impossível ignorar os coletivos que padecem as desigualdades e as formas históricas de pensá-los desde o Estado e suas políticas e instituições. As formas de pensá-las no Estado e nas políticas sócio-educativas têm feito parte de sua reprodução como desiguais.

Ignorar os coletivos vítimas das desigualdades e vê-los apenas como destinatários das políticas termina empobrecendo a visão do Estado e as análises de suas políticas e instituições. Só vendo o Estado, os governos, os entes federados, os poderes, suas leis e diretrizes, como atores sociais e políticos e ignorando o conjunto de atores e de forças, inclusive os coletivos feitos desiguais, termina por produzir análises de políticas pobres, repetitivas. Incapacitados de captar as tensões na sociedade, tornam as análises incapazes de captar as tensões no Estado e nas suas políticas. Tornam-se análises e propostas de políticas lineares, de cumprimento do dever do Estado para a solução dos problemas da sociedade.

Quando o Estado é elevado à condição de ator único, as políticas trazem essas marcas, são políticas compensatórias, reformistas, distributivas. Pretendem compensar carências, desigualdades, através da distribuiçãao de serviços públicos. Os desiguais como problema, as políticas como solução.

Há um pressuposto que orienta essas análises de políticas: o problema está na sociedade e, de maneira específica, o problema está nos pobres, nos coletivos populares, nos setores vulneráveis, em risco, nos coletivos desiguais. Daí a ênfase dada a diagnosticar, caracterizar o problema, as carências, as vulnerabilidades, os desiguais apenas vistos como o locus social onde se concentram os problemas. Os coletivos sociais, raciais, étnicos, dos campos, das periferias urbanas, das periferias regionais são o problema. O Estado é a solução. Em toda análise de 
políticas a lógica é simples: apelemos ao Estado, a suas leis, a seus deveres públicos de ser solução para a fome, o analfabetismo, a falta de escolarização, de escolas, de recursos, de material didático, de formação e valorização dos profissionais. Repete-se a quantidade de documentos e de análises, lembrando ao Estado seu dever de resolver os problemas da sociedade, sobretudo dos coletivos marginalizados, excluídos. Essa persistente visão dos setores populares como problema tem funcionado como mecanismo de sua produção como desiguais.

Nessas análises o Estado não é problema. Pode ser criticado por não ser igualitário na solução dos problemas sociais, por dar maior atenção e mais recursos a uns setores da sociedade do que a outros. O apelo será para que o Estado seja equitativo na função de alocar recursos para solucionar os problemas da sociedade, que as políticas públicas sejam distributivas; que diante das desigualdades o Estado implemente como solução políticas compensatórias para os mais desiguais.

Merece destaque, nessas análises, como a visão que se tem do Estado e de suas políticas para os coletivos desiguais é conformada a partir de como os desiguais são pensados: como problema. Eles são o problema ou porque são preguiçosos, improdutivos, aversos ao trabalho, imprevidentes, ou por não serem escolarizados (analfabetos), sem as competências requeridas pelo mercado de trabalho moderno. Ainda mais, eles são problema porque são desiguais, diferentes em raça, etnia, classe, gênero, em valores, cultura, consciência crítica. Ver as diferenças, os diferentes como problema está incrustado em nossa cultura política. Ou são problema herdado de um passado de tradicionalismo, do atraso na agricultura, no trabalho informal, ou da lenta incorporação na sociedade moderna, letrada, desenvolvida. Sob qualquer ângulo, esses coletivos são um problema social que exige um Estado de solução, instituições e políticas públicas de soluçôes.

Os nomes com que os diagnósticos e as análises nomeiam esses coletivos expressam essa visão ou essa forma de pensá-los como problema. Expressam também a visão do Estado como solução e as políticas públicas reivindicadas como remédios eficazes. Em outros termos, a visão do Estado e das políticas corresponde ao modo de pensar que essas análises têm dos setores diferentes produzidos como desiguais. Enquanto não mudarmos o modo de pensar os desiguais como problema, não mudaremos a visão do Estado e de suas políticas como a solução. 
Torna-se urgente repensar e pesquisar como o Estado é pensado nas análises de políticas, em que medida tem faltado uma crítica da visão do Estado e da visão que predomina nas análises dos coletivos feitos desiguais.

Continuemos perguntando-nos como os desiguais são pensados nas análises de políticas sócio-educativas.

\section{Ocultamento das desigualdades}

A visão das desigualdades e dos coletivos feitos desiguais como problema se alimenta das formas de pensá-los. Podemos observar mudanças nas formas de pensá-los que carregam para as políticas sócioeducativas uma visão reducionista das desigualdades. Uma redução frequente: ver as desigualdades como carências de condições de vida, de emprego, de moradia, de saúde, de renda. Desiguais porque carentes de educação, de letramento, de valores, de competências, de hábitos de trabalho. Desiguais pela falta, logo as desigualdades como problema de carências ou naturais, ou históricas a serem reduzidas, compensadas.

Dessa visão dos coletivos desiguais como carentes se alimentam as autoimagens do Estado, das políticas e das instituições sócioeducativas com a função de suprir carências, de equipar com as habilidades e competências necessárias para diminuir as desiguais condições de inserção na sociedade letrada, na empregabilidade, ao menos na sobrevivência. Políticas de solução de carências para diminuir as desigualdades. Políticas compensatórias, distributivas das competências imprescindíveis para minorar as desiguais condiçôes do viver. Se reduzirmos as desigualdades a carências, caberá ao Estado, a suas políticas e instituições apenas o dever de suprir carências. Um papel menos exigente do que construir uma sociedade igualitária e justa.

Outra forma de pensar os coletivos feitos desiguais é como marginalizados, até como marginais ou na margem de lá, onde predomina a miséria não tanto social mas moral, a falta de valores, de hábitos, onde domina o tradicionalismo e até a cultura da pobreza e da miséria. Desiguais porque à margem da civilização, da modernidade, da racionalidade científica, do progresso e de seus valores civilizatórios, progressistas, de esforço e de trabalho. Situar as desigualdades 
como problema nessas carências morais tem alimentado concepções de políticas sócio-educativas e de projetos comprometidos com solucionar essa condição de marginalidade. Tirar esses coletivos da margem, através de pedagogias civilizatórias, moralizadoras, para passá-los da margem da tradição, do atraso, da imoralidade para a modernidade, o progresso, os valores civilizatórios, a racionalidade científica.

As instituições educativas alimentadas dessa visão das desigualdades se pensam como passagem, percurso da margem de lá para a margem de cá. As políticas e projetos são pensados como solução, como oportunidades oferecidas; como pontes, ao menos como passarelas ou pinguelas para esses percursos de passagem. Ao Estado e suas instituições cabe oferecer essas pontes e passarelas. Mas não para todos indistintamente passarem, através de qualquer percurso. Apenas os esforçados, exitosos, merecerão passar.

Reduzidas as desigualdades a uma marginalidade moral, précivilizatória, pré-moderna, pré-racional, as soluções serão postas em projetos probatórios de ultrapassagem dessa margem com êxito e esforço. É significativo que a pluralidade de projetos sócio-educativos e as políticas educativo-civilizatórias-moralizadoras estejam carregadas de exigências de provar, comprovar, avaliar e atestar passagens exitosas, mais nas condutas, valores, esforços, pontualidades do que no domínio de competências e habilidades cognitivas.

É fácil observar como as políticas pela superação das desigualdades vão se distanciando de políticas distributivas de competências para superar carências de condições de vida e se concentram em políticas compensatórias de carências morais, de valores, de atitudes. Mais educação, mais tempo de escola para tirar da marginalidade, para salvar a criança, o adolescente em risco moral, da violência, da droga, da carência de valores nas famílias populares. Não tanto para salvá-los da fome, da miséria extrema, nem sequer de capacitá-los para a empregabilidade. Essa visão moralista das desigualdades está na moda nas políticas sócio-educativas para os coletivos reduzidos a marginais, desiguais em moralidade. Por aí se avança na imagem do Estado e da escola pública como moralizadores dos coletivos marginais.

Essa visão oculta o que salta a vista: as desigualdades são de condições de viver, de emprego, de sobrevivência, de exploração no trabalho até explorações múltiplas do trabalho infanto-juvenil. O aumento 
da fome, da pobreza massificada deixa ao descoberto a fragilidade dessa visão moralista que vem impregnando as políticas sócioeducativas. Por outro lado, as esperanças ingênuas de tirar os desiguais da marginalidade por meio de projetos sócio-educativos "civilizatórios" se mostram vazias. Saindo de mais umas horas de extraturno, de atividades lúdicas, culturais, esportivas, civilizatórias e moralizadoras, voltam às ruas, às casas, às famílias no desemprego, na sobrevivência nos limites, no trabalho infantil e adolescente, nas saídas mais precárias para sobreviver na pobreza massificada de que são vítimas desde crianças. Os educadores(as) das escolas públicas e desses programas percebem com os educandos os limites dessas políticas, diante do peso da precarização material de suas formas de mal-viver. Redes, escolas e educadores(as) têm encontrado outros significados para esses projetos quando não veem os educandos como carentes morais.

Chegamos a mais uma forma de ocultamento das desigualdades. Para o Estado, suas políticas e programas e para as instituições, escolas e conselhos e para os órgãos de formulação, gestão e avaliação, essas desigualdades mais radicais nas formas materiais de produção do viver serão reduzidas à exclusão. A redução das desigualdades à exclusão entrou na pauta e nos discursos. Desiguais porque excluídos (Moreno, 2005).

A relação entre educação, políticas públicas, Estado e desigualdades vai deixando lugar a políticas de inclusão, escola inclusiva, projetos inclusivos, currículos inclusivos. A categoria desiguais porque na pobreza, no desemprego, na exploração do trabalho, porque oprimidos, sai das justificativas de políticas e até das análises e avaliações e o termo excluídos entra no seu lugar. Excluídos não dos bens materiais do viver humano, mas excluídos dos bens culturais, das instituições e espaços públicos, do convívio social. Mantidos do lado de fora, extramuros.

Ao Estado, a suas políticas e instituiçôes corresponde o dever de incluí-los. De abrir as portas, de permitir o acesso àqueles mantidos fora dos recintos do convívio social e cultural. $\mathrm{O}$ termo acesso de todos à escola se torna a motivação mais repetida. Esse papel includente dos excluídos é mais leve, mais palatável e até mais autoafirmativo do papel do Estado, das suas instituiçōes e políticas do que 
o dever de reduzir as desigualdades. Um papel até benevolente de abrir as porteiras, permitir e propiciar o acesso ao lado de dentro daqueles coletivos pensados e mantidos do lado de fora. Um Estado que abre benevolente as portas, as grades que mantêm os excluídos do lado de fora.

Mais uma vez, as desigualdades mais radicais ocultadas em formas mais leves de pensar os desiguais para afirmar funçōes mais leves do dever do Estado-solução, das instituições e políticas sócio-educativas de solução. Impressiona com que facilidade essa descaracterização das desigualdades passa a ser incorporada nas pesquisas, nas análises, nas justificativas de leis e pareceres, nas políticas curriculares e nos programas sócio-educativos e até nos projetos político-pedagógicos das escolas. As formas de pensar as desigualdades e suas vítimas redefinidas nas formas de se pensar o Estado, as escolas, as instituiçóes normativas, os grupos gestores, formuladores, avaliadores e analistas de políticas de "igualdade". Aliás, de inclusão. Como vai ficando distante o ideário progressista de erradicar as desigualdades pela educação!

O pensamento progressista destacou outra face das desigualdades. Desiguais porque inconscientes, pré-políticos, irracionais ou sem a racionalidade crítica, sumidos na consciência pré-política do senso comum, na consciência falsa, em crenças, tradiçôes e misticismos acríticos. Porque submetidos à consciência e cultura do dominador, do opressor, se mantêm na exclusão, submissão, nas diversas formas de desigualdades. Essa visão não motivou nem políticas nem programas do Estado. Carregava uma visão mais radical, política, das desigualdades, mas nem sempre destacou as desigualdades mais radicais nas possibilidades de produção da existência.

Diante dessas formas de ocultamento, se impóe perguntar-nos: Essa diversidade de formas de ocultar as desigualdades e suas vítimas tem conseguido convencer os coletivos feitos tão desiguais em nossa história de que não passam de carentes, marginais, excluídos, inconscientes? Terão se convencido de que não cabe ao Estado, a suas instituições e políticas enfrentar as desigualdades de suas formas de viver, mas apenas corrigir, suprir carências, moralizá-los e até abrir as portas, dar acesso a instituiçôes inclusivas?

Impõe-se pesquisarmos que significados políticos carregam esse ocultamento e essas visóes reducionistas dos coletivos produzidos como 
desiguais. Pesquisar como essas visōes têm marcado profundamente a natureza das políticas sócio-educativas, do ordenamento legal e do papel e visão do Estado.

\section{As desigualdades como questão social, política}

Essas tentativas de ocultar as desigualdades e de desviar a relação entre Estado, políticas, instituiçóes e desigualdades têm se revelado incapazes de ocultar o crescimento e massificação da pobreza, do desemprego, do trabalho infantil e adolescente, da fome e da precarização brutal das formas de viver (Arroyo, 2010). São os mais desiguais dos desiguais que vão chegando às escolas populares. Quanto mais as desigualdades ficam expostas até no sistema escolar, maiores as tentativas das políticas sócio-educativas de ocultá-las. $\mathrm{Na}$ área social, mais do que na educacional, as desigualdades são reconhecidas como questão social; produzidas por padrōes de concentração da renda e da terra, de destruição da agricultura familiar, pelo aumento das imigrações, dos aglomerados de moradias precaríssimas, do trabalho informal, da sobrevivência nos limites extremos. Nesse quadro, o que preocupa como questão social no Estado e suas políticas educativas são as reaçôes das vítimas, inclusive crianças, adolescentes e jovens, a essa massificação da pobreza e das desigualdades, tanto nos campos como nas periferias urbanas. Preocupa a questão social como ameaça à ordem social e política. Até à ordem escolar.

Os coletivos populares são mais uma vez o problema, ameaçando a ordem social. O Estado, suas instituiçōes e políticas se oferecem como solução. Solução no sentido de manter as reações dos coletivos feitos tão desiguais nos limites suportáveis para a segurança social e política e escolar; manter sob controle não tanto a produção do aumento das desigualdades, mas as reaçôes dos coletivos feitos desiguais, inclusive crianças, adolescentes e jovens. A opção é por políticas de segurança, de ordem, de controle. A questão das desigualdades como questão de polícia, extermínio de adolescentes e jovens, sua classificação como criminosos, violentos, logo, extermináveis. Indisciplinados como alunos, logo, indignos de permanecer na escola

As categorias marginais morais, carentes, excluídos, inconscientes vão ficando distantes como incapazes de dar conta das desigualdades 
como questão social. As políticas sócio-educativas distributivas, moralizantes, compensatórias, inclusivas, conscientizadoras perdem poder de convencimento. Estão em baixa. As políticas sócio-educativas são vistas como de pouca eficácia para a profundidade das desigualdades e para a complexidade da questão social que as reações de suas vítimas provocam. São vistas como políticas lentas, de longo prazo, e ainda exigem a colaboração não confiável do corpo docente e dos educandos. A superação do analfabetismo, o aumento da escolarização, para a inclusão, inserção ordeira na cidadania, no trabalho, na ordem social não são vistas como políticas eficazes, dada a urgência do controle das consequências sociais do aumento das desigualdades, até em adolescentes e jovens. A opção tem sido por políticas de controle, não de convencimento, mas de repressão, expulsão, até de eliminação de adolescentes e jovens "violentos".

Nesse quadro, somos obrigados a nos perguntar que papel cabe ao Estado, às políticas e às instituições educativas? O Estado se mostra sem escrúpulos em seu papel controlador, interventor, restaurador da ordem social. Até as políticas sócio-educativas passam a trazer essa marca de controle da infância, adolescência, juventude exposta e até partícipe da "desordem social". Passou a não ser ocultado que muitos dos programas educacionais têm como destinatários a criança, a adolescência, a juventude "em risco social". A interpretação pode ser dupla: aqueles que estão em risco porque padecem são vítimas das desigualdades, da questão social, ou aqueles que, com suas violências, põem em risco a ordem social e escolar porque vitimados pelas desigualdades. Esta segunda visão tende a predominar nos programas e políticas sócio-educativas (Arroyo, 2007).

Um significado vai ficando manifesto: as políticas sócio-educativas e as instituições não estão isoladas do conjunto de políticas, ações, controles dos setores populares, dos desiguais, inclusive de sua infância, adolescência e juventude, seja vistas em risco dos efeitos da questão social, seja pondo em risco como atores a ordem social e até a ordem escolar. Essas mudanças profundas, de natureza social e política das desigualdades, levam inevitavelmente a mudanças profundas na natureza social e política das políticas, programas e instituiçóes educativas. Muda o papel do Estado-solução. As soluções são outras. Os sonhos de um Estado-solução e de políticas e instituições educativas a serviço da garantia do direito à herança cultural, ao conhecimento, à emancipação, para a superação das desigualdades, ficam cada vez mais 
soterrados no papel de controle, regulação das questões sociais e políticas que o aumento e aprofundamento das desigualdades vêm provocando, até na infância e juventude.

A relação perdida ou ocultada entre Estado, políticas, instituições e desigualdades volta ao primeiro plano, porém em novas e mais complexas indagações para as pesquisas e avaliaçôes, para a sua gestão e análise. Somos obrigados a tentar entender que a produção das desigualdades ou dos Outros como desiguais tem enraizamentos sociais e políticos mais profundos e mais complexos. Diante dessas raízes tão expostas, somos obrigados a repensar o papel do Estado, de suas instituições e políticas. Consequentemente, a rever nossas análises. Quando as desigualdades não são as mesmas, nossas análises não podem continuar as mesmas.

\section{As desigualdades ressignificadas}

Quem questiona de maneira mais profunda e desestabilizadora as desigualdades, os modos de pensá-las e de enfrentá-las são os próprios coletivos pensados e segregados como desiguais. Como se manifestam? Como se pensam e pensam o sistema de produção das desigualdades? Como pensam o Estado, suas instituições e políticas e suas relações com as desigualdades?

Se o aumento e aprofundamento das desigualdades obrigam a enfrentá-las como uma questão social que redefine o papel do Estado e de suas políticas, as reações dos coletivos vitimados em nossa história pelas desigualdades repolitizam os modos de pensá-los como desiguais. Repolitizam o papel do Estado, de suas instituições e políticas. Esses coletivos não se pensam feitos desiguais, porque carentes, nem excluídos ou inconscientes e menos em inferioridades morais, intelectuais, culturais, civilizatórias. O não reconhecimento deles mesmos nas formas inferiorizantes de pensá-los desestabiliza as formas de pensá-los como problema que tem legitimado as formas de pensar o Estado, suas instituições e suas políticas como solução. $\mathrm{Na}$ medida em que não se aceitam como problema, desmontam a visão do Estado como solução.

Há um dado da maior relevância: os coletivos feitos desiguais se fazem presentes na dinâmica social e política. Que significados dão às desigualdades os coletivos feitos desiguais, ao se fazerem presentes na dinâmica social e econômica, política, cultural e pedagógica? 
Um primeiro significado chama nossa atenção: se sabem vítimas das desigualdades, mas afirmam ações pela justiça, igualdade, emancipação. Suas lutas não são por políticas de controle, erradicação, diminuição das desigualdades, mas por políticas de igualdade. A motivação vem de projetos emancipatórios de sociedade, de campo e de cidade, por projetos de Estado, de outras políticas e instituições. De uma agenda pública inspirada em princípios de justiça, equidade, emancipação.

Essa inspiração positiva muda a tradicional relação entre Estado, políticas, instituições e desigualdades. Não partem de ver-se como problema, mas de apontar projetos, mostrando o fracasso da relação tradicional na formulação, gestão e análise de políticas que partem de vêlos pelo negativo, como problema para justificar a oferta de soluções, de políticas compensatórias, distributivas e moralizadoras. Ao se verem como sujeitos de projetos positivos, invertem o significado das políticas, das instituiçōes e do papel do Estado. As políticas oficiais distributivas revelam suas fraquezas quando confrontadas com as açóes positivas dos coletivos por justiça, igualdade, emancipação.

Outro significado relevante é que esses coletivos em ação, afirmação e em movimentos levam suas lutas pela justiça e igualdade às próprias fronteiras da produção das desigualdades, das injustiças e da sua subordinação: a concentração, expropriação do trabalho, da terra, do teto, do espaço urbano, da renda, do conhecimento, as hierarquias de poder sociais, raciais, sexuais. Politizam a produção das desigualdades, situando-a na relação política de dominação-exploração. Mostram as fronteiras onde se produzem as injustiças e desigualdades mais opressoras. O que há de mais radical nos coletivos em ação e em movimentos é que essas mesmas fronteiras que produzem as injustiças viram fronteiras privilegiadas de luta por justiça e igualdade. Mostram que essa diversidade de fronteiras não age de maneira isolada, todas fazem parte dos mesmos padrōes e relaçôes de dominação-subordinação.

Consequentemente, exigem políticas articuladas em todas essas fronteiras. Aí articulam a centralidade dada a suas lutas pelo direito ao conhecimento, à herança cultural, às ciências e tecnologias, à entrada e permanência na educação básica e na universidade, às ações afirmativas, às cotas (Arroyo, 2006). Pressionam por colar as políticas educacionais contra as desigualdades nesses significados de justiça, equidade e 
emancipação. Entretanto, o que se pode observar é que o campo da educação e suas políticas continuam pensando-se isolados dessas fronteiras, onde se dá a produção das injustiças e desigualdades mais radicais e onde os coletivos colocam suas lutas. As desigualdades escolares, educativas, continuam pensando-se como as desigualdades produtoras de todas as desigualdades sociais, econômicas, dos campos e periferias. Consequentemente, as políticas de igualdade de acesso, de permanência na escola básica, em padrões mínimos universais de qualidade, continuam pensadas como redentoras de todas as formas de injustiça e desigualdades.

Os coletivos feitos desiguais em suas ações e movimentos mostram que os processos de sua produção e reprodução como desiguais são mais profundos, mais complexos e persistentes. Que as desigualdades educativas fazem parte dessa complexidade. Exigem ações e políticas não isoladas, mas articuladas, capazes de reverter esses complexos e múltiplos processos de produção. As desigualdades escolares não são subestimadas, antes adquirem maior relevância nesses complexos e múltiplos padrões de produção, manutenção das injustiças e desigualdades e no conjunto de ações coletivas por justiça, igualdade, emancipação.

Outro significado a ser destacado é que esses processos de produção das injustiças e desigualdades não são estáticos, perdurando na atualidade, mas são redefinidos, ressignificados e refinados no contexto atual dos processos de concentração e de apropriação-expropriação da renda, da terra, do espaço urbano, do conhecimento, das ciências e tecnologias, da privatização do Estado, de suas agências e políticas. Essa visão dinâmica traz uma mudança de qualidade e de natureza das desigualdades, não apenas por seu aumento, mas pelo refinamento dos tradicionais processos de sua produção. Essas mudanças que os coletivos experimentam contrastam com a persistência de uma visão estática das desigualdades na educação, centradas no acesso e nos anos, nos percursos escolares, como se quatro ou nove anos de escolaridade hoje tivessem e mesmo poder igualizante do que vinte, quarenta anos atrás, como mecanismo de acesso ao trabalho do campo, da indústria ou do comércio, no trabalho do jovem ou da jovem, do branco, ou negro.

Os coletivos nos diversos movimentos mostram quais são as fronteiras onde as injustiças e desigualdades são mais radicais e onde 
mudam de qualidade e de natureza até as desigualdades escolares. As análises de políticas educacionais são instigadas a pesquisar essas mudanças na natureza e qualidade das desigualdades, no refinamento e na complexidade dos processos de sua produção.

Em que fronteiras se dão essas mudanças? Pensemos em algumas mais próximas ao pensamento sócio-educativo: trabalho e cidadania.

\section{O padrão de trabalho produtor de novas desigualdades}

As políticas educacionais se pensam participando na diminuição das desigualdades, na medida em que capacitam para a inserção no mercado de trabalho. Por aí passa uma das mediações mais destacadas na relação entre educação e superação das desigualdades: capacitar para a empregabilidade, para a disputa menos desigual dos postos de trabalho. "Estude e terás emprego". "Tire o diploma de ensino fundamental, médio e terás trabalho". O acesso ao trabalho como redutor das desigualdades. A inserção social pela educação tem como mediação a inserção no trabalho. Quando essa mediação do trabalho entra em crise, as desigualdades se aprofundam e as políticas educativas perdem significado, entram em crise de legitimação social entre os coletivos desiguais (Frigotto, 1998).

A crise, a escassez de trabalho, o desemprego, a sobrevivência informal, a segmentação e hierarquização do trabalho e da qualificação têm aprofundado e polarizado as desigualdades e desestabilizado a relação tradicional entre educação, trabalho e igualdade. Enfraquecem as políticas e as instituiçóes educativas legitimadas na crença nessa mediação do trabalho. Sua crise e o aumento do desemprego estrutural levam ao enfraquecimento da visão do Estado salvador, controlador das desigualdades por meio de políticas sócio-educativas, de capacitação para a inserção no trabalho. A articulação tão mecânica nas políticas de acesso e permanência, ou de currículos por competências, tendo como mediação o acesso ao trabalho, expõe essas políticas e sua relação com a diminuição das desigualdades ao enfraquecimento e até ao fracasso, sempre que o trabalho entra em crise.

Esta crise do trabalho vem afetando não só o movimento operário sindical, como também o docente. Afeta a relação tão cultivada no pensamento pedagógico emancipatório entre educação-trabalho, como 
princípio educativo. Princípio este de extrema relevância nos projetos de igualdade, emancipação, retomados pelos movimentos sociais, feminista, racial, por exemplo, lutando pela igualdade no trabalho e na educação.

A crise dessa mediação trabalho-educação é um dos elementos que tocam de maneira mais radical na crise da relação entre políticas educacionais e desigualdades. O trabalho, prometido como mediador da correção das desigualdades, torna-se uma das fronteiras mais cruéis de aumento e aprofundamento das desigualdades. O Estadosolução, corretor das desigualdades, passa a cumprir o papel da regulação da crise estrutural do trabalho, seja pela flexibilização dos direitos do trabalho, da estabilidade dos salários, seja deixando as relações de trabalho à mercê do mercado, de sua segmentação ou da polarização entre trabalhos, qualificação, salários. A escolarização básica fica o papel de capacitar para uma inserção precária, instável, nos trabalhos desqualificados.

Enquanto o Estado proclama a universalização do ensino fundamental como superação das desigualdades, sua titulação apenas permite o acesso a empregos desqualificados, elementares, de sobrevivência, reproduzindo e aprofundando as desigualdades, quebrando o vínculo prometido entre escolarização, emprego e igualdade. $O$ trabalho perde a capacidade de mediar a relação entre educação, superação e diminuição das desigualdades e passa a mediar a produção-reprodução e aprofundamento das desigualdades. Escolarizados, mas sem emprego ou em trabalhos precarizados, logo, em formas de viver precarizadas, vulneráveis, instáveis. As desigualdades aprofundadas são polarizadas quando a universalização da escolarização prometia aproximá-las. Esta é uma realidade que nos obriga a repensar relações lineares, mecânicas, entre escolarização, trabalho e igualdades. Obriga-nos a repensar as análises de políticas educacionais.

Boaventura de Sousa Santos (2006, p. 298) sintetiza este quadro:

A transformação do trabalho está a ocorrer um pouco por toda a parte (...). A revolução tecnológica está a criar uma nova e rígida segmentação dos mercados de trabalho a nível mundial, entre uma pequena fracção de empregos altamente qualificados, bem remunerados e com alguma segurança, e a esmagadora maioria de empregos pouco qualificados, mal remunerados e sem qualquer segurança ou direitos. Nesse processo, 
muitas qualificações, aptidões e quase todas as carreiras desaparecem e com elas são lançados na inutilidade social grupos significativos de trabalhadores e os saberes de que são possuidores. Incapazes de reentrar no mercado de emprego, saem de um já cruel sistema de desigualdade para entrarem no sistema de exclusão quiçá mais cruel.

Boaventura vê nesses processos uma metamorfose do sistema de desigualdade em sistema de exclusão. Falar em desigualdade supõe alguma pertença, porém hierarquizada, possível de ser corrigida através de políticas redistributivas. Sobretudo, através de integração pelo trabalho, consequentemente de políticas de preparação, qualificação para o trabalho. A falta de trabalho torna essa integração hierarquizada mais precária. A vulnerabilidade social aumenta ao tornar-se o próprio trabalho e sua qualificação vulneráveis.

O trabalho perde eficácia como mecanismo de integração num sistema de desigualdade para passar a ser um mecanismo de reintegração num sistema de exclusão. Deixa ter virtualidades para gerar redistribuição e passa a ser uma forma precária de reinserção sempre à beira de deslizar para formas ainda mais gravosas de exclusão. De mecanismo de pertença pela integração passa a mecanismo de pertença pela exclusão. (Santos, op. cit., p. 298)

Essa mudança no sistema de desigualdade afeta em cheio a relação entre Estado, suas instituições e políticas educacionais e as desigualdades. Sua eficácia se perde. Quem sente essa perda são os próprios jovens e adolescentes populares, seus educadores(as) e as escolas públicas populares. Suas promessas redistributivas de competências para o emprego e de reinserção no reino das igualdades perdem virtualidade e credibilidade. Difícil convencer esses jovens e adolescentes, até crianças e mesmo adultos da EJA a frequentar a escola, sacrificar tempos e energias, estar atentos, disciplinados, ter bons rendimentos para terem trabalho. Os docentes sabem que essas promessas se tornaram miragem. Nesse quadro tão realista, que sentido tem teimar em repetir velhas lógicas de relações entre educação, trabalho e igualdade?

De alguma forma, o Estado, suas instituições e políticas educativas percebem essa metamorfose do sistema de desigualdade em sistema de exclusão. Vai-se abandonando até o termo desigualdade e o termo na moda passa a ser políticas inclusivas, escola, currículos inclusivos, projetos de mais tempo, segundo turno, mais educação inclusivos. Não 
mais mediadas por promessas de emprego, nem por domínios de competências para o emprego rarefeito e segmentado, mas por promessas de inclusão mediada pelas artes, a música, o esporte, a cultura, a cidadania ordeira, pela autoestima e até pela renovação moral de condutas; pelo esforço, a previdência, o empreendedorismo úteis para a sobrevivência, o trabalho informal, o biscate.

As políticas e projetos sócio-educativos agora se propõem a permitir ou oferecer formas precárias de reinserção social da infância, adolescência e juventude populares, dos excluídos, para minorar seu deslizamento para as formas mais precarizadas de exclusão. $\mathrm{O}$ que se propõem não é tanto a inclusão, mas o não agravamento ainda maior da exclusão. Essas políticas e projetos "inclusivos" funcionam como mecanismo de um Estado regulador das desigualdades e da exclusão, através de políticas de gestão controlada da exclusão. Revelam a face de um Estado que promove, de um lado, a desvalorização, segmentação do trabalho, a flexibilização dos direitos conquistados pelo movimento operário e, de outro, oferece projetos de inclusão educativa.

Podemos continuar com as mesmas análises de políticas, se as desigualdades não são as mesmas, se o Estado não é mais o mesmo e se o trabalho perdeu o poder de mediador na superação das desigualdades? Que políticas pensar quando os jovens e adultos populares, incapazes de entrar no mercado de emprego, saem de um sistema já cruel de desigualdades para entrarem no sistema de exclusão mais cruel? A visão ingênua do Estado-solução está superada.

\section{De políticas de igualdade a políticas de inclusão cidadã}

Até onde mudar de políticas de correção das desigualdades para políticas de inclusão poderá recuperar os sentidos das políticas educacionais?

Os próprios coletivos sociais injustiçados pelas desigualdades resistem a ser pensados como excluídos. Quando o Estado, suas instituiçôes e políticas se desconectam das lutas por justiça e igualdade e se deslocam para medidas de inclusão, participação, vai se perdendo a radicalidade que inspirou a relação entre políticas educacionais e superação das desigualdades. Que significado tem esse deslocamento no campo da educação, exatamente quando os próprios coletivos 
Políticas educacionais e desigualdades: à procura de novos significados

feitos desiguais radicalizam suas ações ao vinculá-las à justiça, equidade, emancipação?

As lutas pela educação do campo ou pela superação das desigualdades de gênero, de orientação sexual ou as açôes do movimento negro por políticas afirmativas, pelo estatuto da igualdade racial no trabalho, no sistema educativo, nas diversas instâncias do poder, no judiciário, são lutas eloquentes por justiça e equidade. Reduzir essas pressões a projetos de precária reinserção em um sistema de exclusão é um desvirtuamento dessas políticas e instituições e da própria função do Estado. A tal ponto que, nos discursos oficiais, não se promete mais acabar nem diminuir as desigualdades. Nem se propōe a avançar para a justiça e igualdade. Há uma desistência de incluir no ideário políticopedagógico essas promessas. Desde o pré-escolar, o letramento ou o numeramento são pensados para instrumentalizar para a inclusão no mundo letrado ou em empregos precarizados. A "Provinha-Brasil" e tantas provas oficiais são testes de capacidades dessa inserção precária sempre à beira de deslizar para os níveis mais gravosos da exclusão social, até dos felizardos que acertam acima da média. Essas provas oficiais atestam os merecedores da inclusão precária e condenam, reprovam milhôes como ainda não merecedores da inserção, nem sequer precária, por seus baixos rendimentos nas provas oficiais.

As crenças nas virtualidades da democratização igualitária pela educação básica perdem credibilidade até no Estado, em suas políticas e instituições educativas. Os discursos políticos e suas promessas se tornaram mais cautelosos e menos pretensiosos, política e pedagogicamente menos radicais, em contraste com a radicalidade política que os coletivos feitos desiguais vêm adotando em suas açôes. Isso porque experimentam que a produção e a vivência das desigualdades do viver são mais radicais.

A guinada de políticas de justiça e igualdade para políticas de inserção precária é um atestado da descrença instalada no Estado, nas suas políticas e no campo da educação de que os desiguais, ainda que escolarizados no padrão mínimo de qualidade prometido, não conseguirão sair dos níveis de pobreza, de sobrevivência, do trabalho informal. Continuarão vivendo em vilas, favelas sem horizontes de superação das desigualdades históricas que os vitimam como coletivos. Reconhecer a perda de credibilidade dessas crenças que tanto inspiraram 
pedagogias progressistas traz um impacto profundo, uma quebra nas autoimagens igualitárias do Estado e de suas políticas e instituições cultuadas como solução. Somos obrigados a construir outras imagens. Buscar outras mediações. Rever nossas análises.

A formação para a cidadania inspirou as políticas educacionais no movimento cívico dos anos de 1980 . No novo quadro sócio-político, a inclusão e a igualdade cidadã pela educação são retomadas.

Por vezes se argumenta que, se essa guinada para políticas de inclusão não conseguir a justiça e igualdade social e econômica, ao menos representará um avanço como políticas de igualdade e justiça cultural e cidadã. A cidadania como mediadora, já que o trabalho perde força mediadora? Desde a década de 1980, o pensamento sócio-político-pedagógico progressista reconheceu e proclamou a cidadania como direito e a educação como garantia da cidadania. Educação para a cidadania, pela participação consciente para a igualdade política. Essa frase exprime uma visão dos coletivos populares como ainda não cidadãos ou em estado de subcidadania, a espera de serem passados para a cidadania plena, desde que educados, civilizados, conscientizados e escolarizados.

Reconheçamos que essa classificação dos Outros em estágio de subcidadania ou de pré-políticos, porque sem escola, ignorantes, irracionais, incultos ou inconscientes, tem sido um dos mecanismos históricos de inferiorizá-los, de torná-los desiguais. Entretanto, a ênfase na educação para a cidadania dos coletivos ainda não cidadãos aderia e legitimava essa perversa e segregadora visão inferiorizante dos Outros, até como sujeitos políticos ou em estado de cidadania condicionada à escolarização. Os classificados como desiguais, porque ainda não cidadãos. A adesão a essa visão segregadora, porém salvadora dos ainda não cidadãos, explicitou as intrincadas articulações entre a produção das desigualdades e inferiorizações dos setores populares e seu não reconhecimento como sujeitos políticos, cidadãos plenos enquanto não educados, escolarizados, conscientizados. A escolarização como decisória da condição de cidadão.

A produção de subcidadãos, da cidadania condicionada, é inseparável em nossa formação histórica da produção e manutenção dos desiguais. $\mathrm{Na}$ medida em que as políticas e projetos educativos se distanciarem das intenções políticas de vincular educação, cidadania e 
igualdade social, econômica, e se pensarem como políticas, projetos de inclusão cidadã perderão as radicalidades de origem.

Uma análise rápida dos projetos de inclusão cidadã revela que não tocam sequer nas formas brutais de produzir os desiguais nas bases materiais do viver, sobreviver, na negação da proteção da vida, do comer, do trabalho, da moradia, da terra e território, da renda, do salário, nem na instabilidade, insegurança e precarização do trabalho. A visão e o trato da cidadania são descolados dessas bases materiais da produção da vida digna e justiça e se privilegiam as manifestaçôes artísticas, culturais, lúdicas, comportamentais, ordeiras, cooperativas, participativas no convício social, harmonioso. Nessas fronteiras é pensada a educação-inclusão cidadã, secundarizando ou ignorando as tensas relações entre essas dimensōes e as relações desses coletivos sociais, cidadãos com o trabalho, a terra, renda, moradia, sobrevivência, justiça, igualdade, emancipação e cidadania. Os limites em que a cidadania é pensada nos projetos enfraquecem a própria relação entre educação, cidadania e inclusão.

Os próprios coletivos pensados como subcidadãos aprenderam que, em nossa história, sua produção como tal foi e continua inseparável da sua produção como inferiores, desiguais no acesso aos bens básicos da produção da existência justa. Garantir essas bases é condição para a cidadania plena. Políticas de inclusão cidadã que ignorem essa base material desigual na produção da cidadania não avançarão na inclusão cidadã.

Os coletivos pensados como subcidadãos ou em uma cidadania condicionada expõem esses limites, ao repolitizarem a sua pertença política nas mesmas fronteiras radicais onde é negado seu pertencimento à comunidade e ao território político. Aponta-se que as políticas de educação cidadã terão de estar articuladas a políticas mais radicais de igualdade e de justiça: trabalho, terra, território, espaço, políticas afirmativas de acesso às instituições públicas. Se o rosto dos subcidadãos é o rosto dos desiguais, em condições de viver, as políticas de cidadania terão de ser inseparáveis de políticas de igualdade e de justiça social. Todo projeto de cidadania nacional terá de passar por um projeto de igualdade, de um justo e digno viver.

Algumas políticas sociais, de renda, contra a fome, de subsistência menos indigna, articulam-se a políticas de escolarização, até a 
reforma agrária se articula ao Programa Nacional de Educação na Reforma Agrária (PRONERA), educação nos acampamentos, assentamentos e lutas pela terra, na reforma agrária. Entretanto, as políticas e os projetos que vêm do sistema de educação, das instituições escolares, pouco avançam na sua articulação com políticas sociais de justiça e igualdade nas bases da produção do viver.

A igualdade cidadã se tornou mais complexa, exigindo redefinir a relação entre educação, cidadania e igualdade. Esta relação tão fecunda tornou-se também mais complexa e exige análises mais aprofundadas. Somos obrigados a dar a devida centralidade a outras mediaçóes na relação entre educação, políticas educacionais e justiça e igualdade.

\section{A produção dos diferentes em desiguais}

Chegamos a um ponto nuclear. Se pretendermos avançar no equacionamento da relação entre educação, políticas, instituiçôes, Estado e desigualdades, nos defrontaremos com questōes radicais: Que coletivos foram pensados e tratados como desiguais? Como foram e continuam sendo produzidos os coletivos diferentes em desiguais em nossa formação social, econômica, política, cultural e pedagógica? Em que processos, padrōes e pedagogias foram produzidos? Como têm resistido, reagido a esses processos? Que políticas apontam para reverter essa produção histórica? Em que fronteiras situam os coletivos diferentes, suas intervençôes por igualdade, justiça e emancipação?

Retomando essas questões nucleares, poderão ser repostas as relações entre políticas educacionais e igualdade e justiça.

Estudos de sociologia política têm avançado nas tentativas de entender a especificidade da produção das desigualdades em nossa formação social. Essa produção é inseparável da forma de pensar e alocar determinados coletivos como desiguais porque diferentes. A relação entre desigualdades e diferenças, ou de produção dos diferentes como desiguais, transpassa a história de nossa formação, desde a colonização. Como foram pensados os povos indígenas, negros, caboclos, quilombolas e como continuam pensados os camponeses, favelados, das periferias urbanas? Como inferiores, como inexistentes, irrelevantes. Não na outra margem, nem do lado de fora, nem desiguais em condições 
de vida, mas colocados e pensados na exterioridade de todo lugar social, político, cultural, econômico. Na existência.

Boaventura de Sousa Santos (2009) nos lembra que o pensamento moderno opera em um sistema de distinções estabelecidas através de linhas radicais que dividem a realidade em dois universos distintos, irreconciliáveis: o universo "deste lado da linha" e o universo "do outro lado da linha". Um pensamento abissal na expressão de Santos. Não de margens, nem de muros, mas de abismos entre trabalhadores, coletivos sociais, étnicos, raciais, de gênero, de orientação sexual. "A divisão é tal que o outro lado da linha desaparece, enquanto realidade, torna-se inexistente e é produzido como inexistente" (p. 23). As desigualdades nas sociedades colonizadas e pós-coloniais são mais radicais ao produzirem os Outros como inexistentes, exteriores, as próprias formas aceitas de inclusão. Os Outros, ao não existirem, não são nem incluíveis.

Quando se pensam as desigualdades como marginalização, exclusão, inconsciência, subcidadania, não se chega a essas formas radicais da produção dos diferentes em desiguais, inferiores, inexistentes na especificidade de nossa formação social. Consequentemente, as políticas para superação das desigualdades, para a moralização, conscientização, inclusão ficam na superfície, repetindo-se incapazes de sequer entender e desvelar os brutais processos de sua produção.

Esses processos abissais de produção das desigualdades radicalizam a produção da subcidadania. A impossibilidade de copresença dos Outros no projeto de nação, de cidadania, leva as desigualdades cidadãs, a segregação em territórios de inexistência, de não reconhecimento, ou a delimitação de territórios de cidadania e de não cidadania. Territórios sem possibilidades de fazer parte sequer da regulação urbana, social, política. Territórios de coerção, de tratos violentos. De polícia. Essa não pertença política, cidadã, justificou seu não reconhecimento nos espaços e instituiçōes públicas, no Estado, até no sistema escolar. Sua entrada na escola pública é saudada como uma concessão. Uma dádiva dos coletivos do lado de cá para os do lado de lá. São os de cá que, com suas benevolentes políticas, se dignam a acolhê-los, ao menos quando crianças, nos territórios do lado de cá. Mas se resiste a sua pretensão de acesso às universidades públicas enquanto não mostrarem mérito. 
A produção das desigualdades esteve e continua associada a processos de não reconhecimento, de inexistência, de não pertença à comunidade política nem territorial. Como consequência as presenças afirmativas dos Outros carregam um profundo significado de pertencimento, de ocupação do espaço público, de espaços urbanos, de terras, territórios, instituições, escolas, universidades, até do Estado. Daí que a entrada na escola e na universidade seja tão importante para os coletivos feitos desiguais, inexistentes, desterritorializados, porque diferentes. Entrar passa a ser um gesto e ritual carregado de significados de existência e de pertença, de disputa e de ocupação de territórios. Significados radicais que dão novos sentidos a dominar o letramento ou numeramento.

Entretanto, os processos de produção dos diferentes em desiguais não são apenas abissais, são sacrificiais: a afirmação de uns coletivos como iguais, existentes, exige o sacrifício de outros coletivos como desiguais, inexistentes. Os Nós racionais, modernos, civilizados, conscientes, brancos, homens, proprietários, como síntese da maioridade humana, exigem pensar e classificar os Outros como pré-modernos, incultos, incivilizados, inconscientes, irracionais, como síntese da imaturidade e da inferioridade humana. "A negação de uma parte da humanidade é sacrificial, na medida em que constitui a condição para a outra parte da humanidade se afirmar enquanto universal" (Santos, 2009, p. 31). A desigualdade dos diferentes enquanto humanos é a forma mais radical de produção das desigualdades.

Reconheçamos que o pensamento pedagógico, as políticas e instituições educativas se alimentam desse caráter sacrificial. Veem os diferentes como na minoridade humana. Até como pré-humanos, a ser conformados humanos, ser levados à maioridade pela educação escolar. $\mathrm{O}$ acesso à escola, o letramento, o numeramento, as disciplinas, o mérito serão uma exigência desse percurso de humanização. Os milhões que fracassarem serão sacrificados como analfabetos, desescolarizados, reprovados, com problemas de aprendizagem, defasados. Continuarão catalogados como pré-humanos, jovens ou adultos, mas na inferioridade porque na irracionalidade, movidos a instintos, ao senso comum, com problemas de aprendizagem e de condutas. Essas lógicas marcadas por dicotomias, abismos de sucesso-fracasso, operam sacrificando milhões como fracassados na ignorância e irracionalidade 
Políticas educacionais e desigualdades: à procura de novos significados

para exaltar os merecedores de sucesso, porque esforçados, racionais, inteligentes. Dessa lógica sacrificial, produtora dos diferentes como desiguais, se alimentam o pensamento moderno, a pedagogia moderna e até a empreitada pedagógica-catequética colonial e pós-colonial. ${ }^{1}$

Essa lógica sacrificial é tão persistente que, quando pensávamos ter avançado para a diminuição das desigualdades ao menos educativas pela universalização do acesso, se inventam nas escolas públicas populares novos parâmetros de classificação das desigualdades: a necessidade de provar, em avaliações nacionais e internacionais, a passagem para o reino da igualdade educacional, atingindo parâmetros mínimos de qualidade. Milhões de crianças e adolescentes, de jovens e adultos pertencentes aos coletivos diferentes, pensados como desiguais, como inferiores, pré-humanos, serão reprovados, sacrificados como ainda no reino das velhas desigualdades e inferioridades sociais, étnicas, raciais, do campo e periferias. Como fracassados.

Mas esse novo mecanismo sacrificial não será reconhecido como uma produção, nem do Estado, nem dos padrôes de trabalho, de concentração da renda ou da terra, nem das políticas e instituições. Os próprios desiguais serão responsabilizados como se autossacrificando por seus fracassos no percurso que lhes prometia transpassar o abismo, do lado de lá, das desigualdades para o lado de cá das igualdades. Os diferentes, atestando em avaliações suas inferioridades de origem. As lógicas do sistema escolar parecem sintetizar o pensamento moderno abissal e sacrificial.

Qual a força desse pensamento que resiste a tantos esforços de tantos educadores(as) por fazer do sistema escolar um território de igualdade, de justiça e de emancipação? De garantia de direitos? Estas constatações nos obrigam a redefinir as políticas, a gestão, as análises, as concepções e estratégias político-pedagógicas. Nos apontam a urgência de dar maior centralidade aos esforços de tantos educadores(as) e a radicalidade de açóes coletivas pela garantia dos direitos. Nos obrigam a pesquisar e entender com maior profundidade os processos históricos de produção dos coletivos diferentes em etnia, raça, classe, gênero, orientação sexual, do campo e das periferias como desiguais, inferiores, sub-humanos. A radicalidade persistente desses processos históricos exige políticas também mais radicais. 
Aníbal Quijano (2005) nos lembra que na América as relações sociais se fundaram na ideia de raça, produzindo identidades sociais, historicamente novas: índios, negros, mestiços, brancos.

$\mathrm{Na}$ medida em que as relações sociais que se estavam configurando eram relações de dominação, tais identidades foram associadas às hierarquias, lugares e papéis sociais correspondentes, como constitutivas delas, e, consequentemente, ao padrão de dominação que se impunha. Em outras palavras, raça e identidade racial foram estabelecidas como instrumentos de classificação social básica da população. (p. 228)

As consequências na produção das desigualdades persistem. A ideia da raça, etnia, como uma maneira de outorgar legitimidade às relações de dominação, como uma nova maneira de legitimar as relações de superioridade-inferioridade. Raça, etnia reforçando as desigualdades sociais, sexuais, culturais. Até as desigualdades no padrão de trabalho, de poder-saber, transpassadas por sexismos e racismos. Quijano (op. cit.) nos lembra que as novas identidades produzidas sobre a ideia de raça foram associadas à natureza dos papéis e lugares na nova estrutura global do controle do trabalho. Raça e divisão do trabalho foram estruturalmente associadas, reforçando-se mutuamente. Uma relação segregadora que até hoje opera associada à divisão sexual. As mulheres negras são as mais segregadas em postos de trabalho e salários. Os homens negros, bem distantes dos homens brancos na divisão do trabalho e em salários. Em tempos de crise do trabalho, o sexismo e o racismo operam de maneira mais segregadora.

Chama a atenção que uma relação tão estrita entre raça, gênero, orientação sexual e divisão do trabalho e pertencimento cidadão não seja destacada nas análises de políticas educacionais em suas relaçóes com as desigualdades. Talvez porque ainda o pensamento educacional vê gênero, etnia e raça em uma situação natural de inferioridade, que vê essas diferenças como configurantes da inferioridade intelectual, cultural, moral, civilizatória. Em realidade, esse pensamento pedagógico participou desde a empreitada colonial da produção de uma visão negativa inferiorizada das identidades raciais, étnicas, no próprio campo intelectual, moral e cultural.

Quijano (2005) nos ajuda a entender esses processos de nossa formação. A produção dessas identidades étnicas, raciais, negativas, inferiorizadas teve duas implicações: 
A primeira, todos aqueles povos foram despojados de suas próprias e singulares identidades históricas. A segunda, sua nova identidade racial, negativa, implicava o despojo de seu lugar na história da produção intelectual e cultural da humanidade. Logo, raças inferiores, capazes somente de produzir culturas inferiores. O padrão racista de poder implicava um padrão cognitivo e cultural racista. (p. 249)

As resistências a vincular políticas educativas com as desigualdades raciais talvez expressem o reconhecimento da persistência desses padrões cognitivos racistas. Que lugar tem esses padrões nas análises de políticas? Por que a resistência a intervir de maneira mais radical nas estruturas, rituais e culturas que reproduzem esses padróes?

\section{Pela refundação do Estado das políticas?}

O mais desestabilizador de nossas políticas, de sua formulação, gestão, avaliação e análise é a presença afirmativa dos coletivos diferentes feitos desiguais como sujeitos políticos e, mais, como sujeitos de políticas. Presença afirmativa na dinâmica econômica, social e política, cultural e pedagógica. Contestando o papel do Estado, de suas políticas e instituições e propondo e pressionando por políticas do campo, dos territórios, de moradia, de acesso a espaços urbanos, de trabalho, de acesso e permanência no sistema educacional, por açôes afirmativas, políticas de renda, de comida, de justiça e equidade. Os coletivos feitos desiguais se afirmam presentes como sujeitos políticos e de políticas no espaço público, e na agenda pública se afirmam como sujeitos de soluçôes políticas.

Como sujeitos organizados, em ações coletivas, em movimentos, abrem espaços na administração pública, em ministérios, secretarias, no MEC/SECAD, nas secretarias da Mulher, da Promoção da Igualdade Racial, na Secretaria Nacional de Direitos Humanos, nos conselhos, nas universidades, nos fóruns, na CONAE, no PNE...

Quando outros atores políticos organizados entram em cena, as políticas são pressionadas a se repensar. O próprio Estado tem de ser repensado e o público refundado. $\mathrm{O}$ que pode significar esse reconhecimento dos coletivos populares organizados na administração pública? Como tem sido processada sua presença? O Estado, suas instituiçóes e políticas passam a ser territórios em disputa. Reconheçamos: 
nesse quadro, o papel do Estado, a formulação e a análise de políticas não podem ser os mesmos. Que novos significados estão postos?

Um primeiro significado é não ser sustentável a visão desses coletivos como destinatários distantes de políticas benevolentes. Não há como não reconhecer sua presença ao menos como um incômodo social e político. Quando predomina essa visão, a tendência é para uma inclusão simbólica, para a cooptação. Uma forma de regulação social dos coletivos incômodos. Descaracteriza-se sua presença afirmativa, política, com respostas e com políticas paternalistas, inclusivas, benevolentes. $\mathrm{Na}$ tradicional relação de uso das políticas como cooptação. Não tem sido fácil nem eficaz o uso de políticas, até de espaços na administração pública como mecanismos de cooptação de movimentos tão politizados. A resposta dos movimentos sociais tem sido ocupar esses espaços para políticas mais democráticas de igualdade e de justiça. Para democratizar os processos de sua formulação, gestão e implementação. Para democratizar o Estado.

Os movimentos sociais de dentro dos espaços públicos abertos pressionam por outros estilos, outros critérios de políticas. Outras políticas. Outros atores políticos. Outro Estado. Esse dado não tem como não ser percebido ou reconhecido nas análises de políticas sócioeducativas. Difícil continuar vendo o Estado-solução como o ator único. Difícil manter como papel das associaçóes educativas, de pesquisa, formação, gestão, ensino e didática a tarefa de lembrar ao Estado seus deveres para com os coletivos populares, mantidos e esquecidos como desiguais. Não estão mais fora, do lado de lá, mas estão dentro.

Entretanto, sua condição de meros destinatários ainda continua. Sua presença na sociedade, nas cidades, nos campos e nos espaços da administração púbica, inclusive educativa, continua secundarizada e até ignorada. A ignorância dos coletivos em ações e movimentos na sociedade e no Estado e suas instituições é um dos traços mais empobrecedores das análises das políticas públicas e do próprio Estado.

Um segundo significado é que escutar sua voz é pouco, eles exigem mais. Quando não dá mais para ignorar essa presença e até quando abrem espaços na administração pública, uma postura frequente tem sido reconhecer os coletivos e seus movimentos apenas como canais de chegada das desigualdades, dos problemas que padecem, até às instituições públicas para seu exame, ponderação e tradução em 
políticas e projetos pelos órgãos e atores competentes, formuladores, gestores e analistas de políticas. Esse reconhecimento é reducionista, se limita a uma escuta benevolente de sua voz. Se as próprias vítimas das injustiças e desigualdades históricas aprenderam a falar com suas ações e reivindicações, cabe ao Estado e seus gestores não apenas escutar suas vozes, mas reconhecer suas ações coletivas, como formas de intervenção política. Aos formuladores, gestores e analistas cabe o papel de dialogar com essas ações e intervenções e elaborar as políticas mais eficazes, incluindo coletivos feitos desiguais como sujeitos partícipes de decisóes. Nada fácil avançar no reconhecimento dos coletivos populares e de suas organizaçóes e movimentos, como atores, políticos e sujeitos de políticas.

Esse reconhecimento supõe uma tensão no próprio campo das políticas, na medida em que se contrapõe à manutenção do caráter tradicional do Estado, de suas instituições e órgãos de gestão e de suas políticas, em nosso caso, educativas. Contrapóe-se à manutenção dessa imagem-função tradicional dos coletivos populares como problema e do Estado e suas políticas como solução.

Terceiro significado: reconhecê-los como atores políticos exigirá reinventar o Estado e suas políticas e análises. Os coletivos populares, suas organizaçóes e movimentos em sua diversidade repolitizam a relação com o Estado, suas políticas e órgãos públicos para a garantia de seus direitos. Repolitizam, com suas ações e intervenções, o papel do Estado, seja nas lutas por terra, teto, espaço, saúde, educação... Não pretendem desresponsabilizar o Estado de seus deveres políticos. Há consciência de que ao Estado cabe a função de garantir, como agente político, os direitos, a cidadania, a educação. Mas têm consciência de que o Estado e suas instituiçôes e políticas, se pensados como atores políticos únicos, não têm tido condições dessa garantia. Têm experiência histórica dos limites do Estado e de suas políticas e instituições. As resistências a reconhecer os movimentos sociais como atores políticos passam por sua coragem de apontar esses limites. Uma lição importante para as análises de políticas: pressionar os deveres do Estado, conscientes dos limites do Estado.

Se não há mais lugar para a ignorância do papel político dos coletivos populares e de suas organizaçóes na garantia dos direitos e nas políticas de igualdade e de justiça, nem tem sentido a ilusão da 
substituição do Estado, que alternativas estão em jogo? Avançar para mecanismos e estratégias de complementaridade entre atores, sujeitos políticos, de políticas? Complementaridade não numa espécie de reparto de funções. Os coletivos mostram as desigualdades e injustiças históricas e os processos que as produzem e os agentes políticogestores-analistas do Estado os traduzem em políticas, normas e intervenções. Mas complementaridade no próprio campo da formulação de políticas, de opções, de estratégias, reconhecendo os movimentos sociais como sujeitos políticos, de ação política; reconhecendo que, sem essas ações, lutas, intervenções dos coletivos populares em movimento, as desigualdades e injustiças não serão superadas, nem sequer no campo da educação, da infantil a superior.

Os compromissos progressistas de tantas instituições educativas, de pesquisa e gestão e de tantos gestores, elaboradores e analistas de políticas e de tantas associações não têm sido capazes de reverter o crescimento histórico das injustiças e desigualdades. Reconheçamos que as lutas e mobilizações dos próprios coletivos injustiçados têm sido mais eficazes, porque mais radicais. Porque mostram e tentam reverter os padrôes produtores das desigualdades. Trazem ao embate político esses padrôes. Sem o reconhecimento dos coletivos organizados na garantia dos direitos, especificamente à educação, pouco avançaremos. A complementaridade entre Estado, seus agentes e instituiçóes e os coletivos organizados aponta para políticas e intervençóes mais radicais na garantia dos seus direitos. A ação do Estado se alarga e se aprofunda. Torna-se mais política.

Esses pontos são nucelares: primeiro, as ações coletivas dos setores diferentes feitos tão desiguais apontam e focalizam suas lutas nos padrôes históricos de produção das desigualdades, os padrões de concentração, apropriação da terra e do espaço, do trabalho, da riqueza coletiva, do conhecimento, do poder, até das instituições públicas, do sistema educacional e do Judiciário. Segundo, colocam suas lutas no campo dos direitos, da justiça, equidade e emancipação. Terceiro, explicitam os padróes sexistas e racistas dessa produção. Pontos nucleares para repensar as políticas sócio-educativas.

O quarto significado: repolitizar o campo do Estado e das políticas. A complementaridade de sujeitos e de políticas pressupõe a existência de análises mais radicais sobre a produção das desigualdades e 
de propostas, de interesses contraditórios entre o Estado, seus interesses e sua função reguladora das desigualdades e dos desiguais. Supóe reconhecer e abrir espaços para a manifestação de confrontos e embates de interesses, de projetos de sociedade, de campo, de políticas agrária, urbana, educativa. De sua articulação. As experiências de presença dos coletivos em movimentos na administração pública, nas escolas, universidades, nos ministérios e secretarias têm sido marcadas, como era de se esperar, por confrontaçōes e tensōes políticas, não apenas administrativas. O que é próprio da relação política em que foram feitos desiguais. Pretender elaborar, escolher e implementar políticas de consenso na área dos direitos negados, da produção histórica das injustiças e desigualdades sem confrontos é ingenuidade, sobretudo quando os próprios coletivos feitos desiguais se afirmam na cena política, pública. Porém, formular políticas des-politizadas, geri-las na paz e no consenso e silenciamento de tensōes é mais fácil e mais "eficiente" para visões e práticas de gestão des-politizantes.

Chegamos a um ponto nuclear, a entrada e presença dos coletivos em movimentos no espaço da gestão pública e de políticas exigem a recriação dos espaços públicos, das políticas públicas e sua gestão como espaços políticos de tensão e confronto de interesses. Confronto de projetos não de medidas pontuais, nem apenas de corpos normativos. Tanto a produção como a superação das desigualdades passam por reaçōes políticas tensas, por confrontos, o que exige a explicitação dessa densidade política, de um lado, do Estado e das políticas e, de outro, da presença dos coletivos em movimento. Exige reconhecer que as desigualdades e injustiças, as inferiorizaçōes dos coletivos sociais, étnicos, raciais, de gênero e orientação sexual, do campo e das periferias, enfim, a produção dos diferentes em desiguais é uma produção histórica que se deu e se reproduz nas relaçôes políticas racializadas de dominação-subordinação, nos padrōes de apropriação-segregação dos bens de produção da existência: o trabalho, a terra, a renda, o espaço com centralidade. Ignorar essa relação política é ingenuidade. Relação política que se ignora na visão do Estado-solução e das políticas como meros processos gestores, técnicos, de definição de leis, de estratégias ou de alocação de recursos.

O quinto significado: a refundação político-democrática do Estado. Frente a essas posturas corretivas, despolitizadas, os movimentos sociais apontam a repolitização das políticas, das análises e de sua gestão e, sobretudo, a repolitização, refundação político-democrática do Estado e 
da administração pública. Abrir-se a diversidade de sujeitos não apenas àquelas classes que produzem as desigualdades, nem apenas a um corpo técnico-gestor-normativo compromissado, formulador e analista de políticas. Mas abrir-se aos próprios coletivos que padecem as desigualdades, que lutam de maneira organizada por justiça e equidade.

A refundação político-democrática do Estado, do público e das suas organizaçóes e políticas exige a presença desses atores políticos, que não mais esperam pacientes e agradecidos as políticas benevolentes contra as desigualdades, mas já mostram sua capacidade de equacioná-las e de lutar para sua superação, evidenciando e atacando os processos de sua produção histórica.

Sua presença como sujeitos políticos, de políticas, redefine o campo das políticas, seus critérios, prioridades e sua natureza. De políticas compensatórias, distributivas, corretivas das desigualdades que o mercado, a concentração da terra, da renda e do espaço, do conhecimento e do poder produzem, esses coletivos defendem políticas afirmativas, de diferenciação positiva, não genéricas. Políticas focadas, contextualizadas. Políticas de reconhecimento e não de compaixão com os desiguais porque inferiores em classe, etnia, raça, gênero, campo ou periferia.

Essa mudança na natureza das políticas é uma das contribuições com maior densidade política vinda da presença dos coletivos feitos desiguais no espaço público refundado. Pressionando por refundar o Estado, pressionam por refundar as políticas.

Recebido em março de 2010 e aprovado em abril de 2010.

Nota

1. Exploro essas análises de Boaventura de Sousa Santos no texto: Ações coletivas e conhecimento (no prelo).

\section{Referências}

ARROYO, M.G. Los movimientos sociales y la construcción del derecho a la educación. In: SACRISTAN, J.G. (Org.). La reforma necesaria: entre la política educativa y la practica escolar. Madrid: Morata, 2006. p. 123-143. 
ARROYO, M.G. Quando a violência infanto-juvenil indaga a pedagogia. Educação \& Sociedade, Campinas, v. 28, n. 100, p. 787-807, 2007.

ARROYO, M.G. Los colectivos depauperados repolitizan los currícula. In: SACRISTAN, J.G. (Org.). Saberes e incertidumbres sobre el curriculum. Madrid: Morata, 2010. p. 128-148.

FRIGOTTO, G. (Org.). Educação e crise do trabalho. Petrópolis: Vozes, 1998.

MORENO, A. Superar a exclusão, conquistar a equidade: reformas, políticas e capacidades no âmbito social. In: Lauder, E. (Org.). A colonialidade do saber: eurocentrismo e ciências sociais. Perspectivas latino-americanas. Buenos Aires: ClACSO, 2005. p. 187-202.

QUIJANO, A. Colonialidade do poder, eurocentrismo e América Latina. In: Lauder, E. (Org.). A colonialidade do saber: eurocentrismo e ciências sociais. Perspectivas latino-americanas. Buenos Aires: CLACSO, 2005. p. 227-278.

SANTOS, B.S. A universidade popular dos movimentos sociais. In: SAnTos, B.S. A gramática do tempo: para uma nova cultura política. São Paulo: Cortez, 2006. p. 167-177.

SANTOS, B.S. Para além do pensamento abissal: das linhas globais a uma ecologia de saberes. In: Santos, B.S.; Menezes, M.P. (Org.). Epistemologias do Sul. Coimbra: Almedina, 2009. p. 23-71. 